\title{
The hatching of cereal cyst nematode (Heterodera avenae) in response to different inorganic ions
}

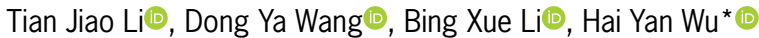

University Guangxi/Agricultural College of Guangxi - Key Lab of Agric - Environment and Agric - Products Safety, Daxue Road, 100 - 530004 - Nanning - China.

${ }^{*}$ Corresponding author <whyzxb@gmail.com>

Edited by: Roy Neilson / Paulo Cesar Sentelhas

Received March 14, 2020

Accepted August 27, 2020
ABSTRACT: Cereal cyst nematode is a major pest of small grain cereals, which causes huge yield losses to crops in China and other parts of the world. In this study, the effects of five inorganic ion concentrations on egg hatching of Heterodera avenae were studied. Results revealed that $\mathrm{ZnCl}_{2}$ and $\mathrm{FeCl}_{3}$ promoted hatching of induced and natural diapausing eggs. The cumulative hatching rates of eggs were $49 \%$ and $13 \%$ at $30 \mathrm{mM} \mathrm{ZnCl}$, and $10 \mathrm{mM} \mathrm{FeCl}_{3}$, respectively, which were higher than those of other treatments. The hatching ability promoted by $\mathrm{ZnCl}_{2}$ is greater than by $\mathrm{FeCl}_{3}$. Diapause induced eggs in $\mathrm{ZnCl}_{2}$ continued to hatch after 10 days; however, those in $\mathrm{FeCl}_{3}$ mainly hatched in the first two weeks. $\mathrm{ZnCl}_{2}$ had obvious stimulating effects on the hatching of natural diapause and non-diapause free eggs at 15 and $30 \mathrm{mM}$ concentrations. $\mathrm{FeCl}_{3}$ promoted the hatching of natural diapause eggs; howevr, it inhibited hatching of non-diapause free eggs. Conversely, different concentrations of inorganic ions did not have any stimulatory effect on white female eggs. In the nematode life cycle, hatching is the critical stage because juveniles may be infected. The results of this study provide useful information the use of new fertilizers (including promoted hatching inorganic ions) applied before planting for controlling nematode diseases caused by $\mathrm{H}$. avenae.

Keywords: hatching rate, ion concentration, stimulus, plant-parasitic nematodes

\section{Introduction}

Cereal cyst nematode (CCN), Heterodera avenae, is widespread throughout Europe, the Mediterranean region of Africa, Asia, North America and Australia and has caused considerable damage to small grain cereals (Wu et al., 2014). Yield loss on wheat caused by CCN varies in many countries due to different climatic conditions, reaching up to $50 \%$ in Australia (Toumi et al., 2017), 40-92 \% in Saudi Arabia (Ibrahim et al., 1999), 40-50 \% in India (Mathur et al., 1980), and 16-55 \% in China (Hou et al., 2012). As chemical nematicides are toxic to humans, animals, and the environment, environmentfriendly biological control microorganisms have been screened and applied (Zhang et al., 2017). Species of Verticillium have often been reported as dominant egg parasites of cereal cyst nematode $H$. avenae Woll (Kerry et al., 1982; Dackman and Nordbring-Hertz, 1985), in addition to the parasitic and lethal effects of Trichoderma longibrachiatum on $H$. avenae (Zhang et al., 2014).

Hatching is a key and vulnerable period in the life cycle of nematodes. Studies have shown that hatching inhibition is effective in reducing nematode population inside or near the roots and even in soil, therefore, hatching could be an ideal stage to apply control strategies against nematode disease (Masler and Rogers, 2011). However, nematodes usually enter a diapause state to resist the harsh environment during the longterm biological evolution (Yen et al., 1995) and diapause of most nematodes occurs during the hatching stage (Palomares-Rius et al., 2013). Some experiments have shown that external environmental conditions, such as temperature, humidity, and metal or inorganic ions, may affect the hatching of nematodes (Jing et al., 2014; Vandenbossche et al., 2015). Zinc salts have shown effects on in vitro hatching of some plant-parasitic nematode species, including $H$. glycines (Behm et al., 1995; Charlson and Tylka, 2003), H. trifolii (Steele et al., 1982), H. schachtii, H. carotae (Clarke and Shepherd, 1965; 1966), and Globodera tabacum (Čepulyte்-Rakauskienè and Būda, 2015). Some inorganic ions, such as $\mathrm{NO}_{3}{ }^{-}$and $\mathrm{NH}_{4}{ }^{+}$, have also been reported to inhibit the emergence of $H$. glycines (Lehman et al., 1971). In a previous study, $0.05 \mathrm{mM}$ of lanthanum chloride inhibited the hatching of G. rostochiensis (Clarke and Hennessy, 1981). Clarke and Shepherd (1966) indicated that ions affect hatching of Heterodera according to the different species, ions, and concentrations.

Inorganic ions usually contained in the soil and fertilizer can affect nematode hatching and influence the life cycle and infective behavior of nematode. However, information is limited on the effects of inorganic ions under the precise concentration gradient on $H$. avenae. This study aimed to investigate the effects of different ions at different concentrations on the emergence of $H$. avenae, which may contribute to a better understanding of the hatching mechanism and provide useful information for the development of new strategies.

\section{Materials and Methods}

\section{Chemicals}

We prepared $70 \%$ ethanol, solution of $\mathrm{Ca}^{2+}, \mathrm{Mg}^{2+}, \mathrm{Fe}^{3+}$, $\mathrm{Zn}^{2+}$, and $\mathrm{Cu}^{2+}$ by $95 \%$ ethanol, $\mathrm{CaCl}_{2}, \mathrm{MgCl}_{2} \cdot 6 \mathrm{H}_{2} \mathrm{O}$, $\mathrm{FeCl}_{3} \cdot 6 \mathrm{H}_{2} \mathrm{O}, \mathrm{ZnCl}_{2}$, and $\mathrm{CuCl}_{2} \cdot 2 \mathrm{H}_{2} \mathrm{O}$, respectively. 


\section{Experimental nematodes}

Samples were collected from a nematode infected field located in Hutun Town, Feicheng County, Tai'an City, Shandong Province, China $\left(116^{\circ} 36^{\prime} \mathrm{E}, 36^{\circ} 12^{\prime} \mathrm{N}\right.$, altitude 77 a.s.l) in 2015. The wheat-maize rotation system was used in the field. Wheat was sown on Oct 3, and harvested on Jun 10 on the following year and maize planted on Jun 20 then harvested in mid-Sept. White females and cysts were extracted via washing and screening methods (Li et al., 2020). Eggs from four sources were used in this study: (1) Natural diapause eggs. The cysts were extracted from the rhizosphere soil of wheat during harvest time (mid-Jun). (2) Eggs inside immature cysts. The immature cysts were separated from the soil collected from infected wheat during the anthesis stage (midMay). (3) Natural non-diapause eggs. The cysts were collected from the infected soil in Nov. The eggs inside the cysts completed their diapause after undergoing low temperature. (4) Diapause induced eggs. The fresh brown cysts, which were collected on Jun 10 in rhizosphere soil of wheat, were incubated at $4{ }^{\circ} \mathrm{C}$ for two months and then the temperature was increased to $15{ }^{\circ} \mathrm{C}$ for hatching (Jing et al., 2014). No juvenile hatched from the cyst after one month of incubation and the eggs inside the cyst were diapause induced eggs.

\section{Egg development stage in white female}

Egg is an important stage of the nematode life cycle, and the successful development of eggs is the continuation of population. In the experiment, the development of a single egg was tracked to evaluate the development of eggs. White females extracted from the rhizospere soil of wheat roots on May 22, 2015, 108 healthy females with similar size were selected under a stereoscope (magnified $20 \times 1$, and then soaked with $70 \%$ ethanol for 3 min for surface disinfection. Afterward, they were thoroughly washed with sterile water. The eggs were then released with a sterilized dissecting needle and dispensed into a 96-well plate, with one egg per well with $200 \mu \mathrm{L}$ of sterile deionized water and incubated at $15{ }^{\circ} \mathrm{C}$. The developmental state of eggs was recorded every six days with an inverted SMZ168 microscope according to Calderón-Urrea et al. (2016). Different letters were used to represent the developmental stages of the embryo: A represented the egg with the most common stage in development of $H$. avenae, B denoted a stage in which the eggshell was covered with closely-packed round globules with uniform diameter named single-cell stage, after the first cleavage the eggs splited into two cells calld two-cell stage which was the stage represented by $C, D$ and $E$ were the four-cell stages with four cells after the second cleavage, F - L represented the embryo as masses of small cells produced after multiple divisions, $M$ was the early tadpole stage, during which the embryo divided unequal one end was dark and the other was transparent that caused germ differentiation, $\mathrm{N}$ was the tadpole stage, onethird of the embryos were dented in this stage, and O denoted the larval stage with a completely stylet structure (Schulze and Schierenberg, 2011).

\section{Bioassay of inorganic ions on the hatching of $\boldsymbol{H}$. avenae eggs from brown cyst}

We prepared $60 \mathrm{mM}$ ferric chloride, calcium chloride, magnesium chloride, zinc chloride, and copper chloride solutions and were used as stock solutions. To obtain different concentrations of ions, stock solutions were diluted to $10,20,30,40,50$, and $60 \mathrm{mM}$. The cyst was surface-sterilized with $70 \%$ ethanol for 3 min and then washed thoroughly with sterile distilled water. The eggs were then released with a sterilized dissecting needle. The egg suspension was composed of sterile deionized water. $100 \mu \mathrm{L}$ aliquot ions solutions of different concentration ions and $100 \mu \mathrm{L}$ eggs suspension were transferred into a 96-well plate to obtain $5,10,15,20,25$, and $30 \mathrm{mM}$ solutions, 40 - 50 eggs each well, and incubated $15{ }^{\circ} \mathrm{C}$, deionized water with eggs as control, with three replicates. The initial eggs and J2 in each well were recorded under the inverted SMZ168 microscope. Emerging juveniles were counted every three days to determine the hatch rate. The cumulative hatching rate was calculated as follows: hatching rate $=$ (number of hatched $\mathrm{J} 2$ / number of initial eggs) $\times 100 \%$. To study the effects of $\mathrm{Fe}^{3+}$ and $\mathrm{Zn}^{2+}$ on the hatching of $H$. avenae eggs, the hatching rates of eggs at concentrations $3,6,9,15,18$, $21,24,27$, and $30 \mathrm{mM} \mathrm{Fe}^{3+}$ and $\mathrm{Zn}^{2+}$ were investigated with three replicates and deionized water as control. Incubation temperature, observation time point, and hatching rate calculation were all similar as described above.

\section{Bioassay of inorganic ions on the hatching of $\boldsymbol{H}$. avenae white females}

Preparation of five ionic solutions with different concentrations was the same as above. White females were surface-sterilized with $70 \%$ ethanol for $3 \mathrm{~min}$ and then washed thoroughly with sterile distilled water. Different inorganic ion solutions with $5,10,15$, 20,25 , and $30 \mathrm{mM}$ concentrations were transferred into a 96 -well plate, $200 \mu \mathrm{L}$ ionic solutions in each well with one white female, deionized water as control with 10 replicates, incubated at $15{ }^{\circ} \mathrm{C}$. J2s were counted every seven days. The hatching rate was calculated as follows: hatching rate $=$ (number of $\mathrm{J} 2 /$ number of total eggs in female) $\times 100 \%$.

All the experiments in this study were repeated twice. 


\section{Analyses}

Data were subjected to analysis of variance (ANOVA) with SPSS 12.0. The LSD method was used to determine significant differences between treatments, and differences in the means were separated by LSD at $p<$ 0.05. All graphs were drawn using SigmaPlot 10.0. The data were analyzed in Microsoft Excel 2010.

\section{Results}

\section{Development of eggs inside white females}

In an early observation, most eggs were in the early morphological stage of development (Figure 1). Eggs observed in the $\mathrm{N}$ stage accounted for $21 \%$, followed by B stage (19\%) and oocytes in the $\mathrm{O}$ and L stages (13 $\%$ in each stage). The other eggs were at other different early stages with a relatively low proportion. During incubation, with the extension of incubation time, eggs at different stages gradually developed and matured, eggs of the $\mathrm{N}$ and $\mathrm{O}$ stages gradually increased. In the $\mathrm{O}$ stage, a positive correlation was seen between cumulative hatching rate $(\mathrm{y}: \%)$ to time $(\mathrm{x}: \mathrm{d})$, as calculate by the linear equation $\mathrm{y}=2.026 \mathrm{x}+14.459, \mathrm{R}^{2}=0.9635$. The number of eggs reached $73 \%$ at 30 day after incubation (DAI).

\section{Effects of different inorganic ions and different concentrations on the hatching of diapause induced eggs}

The hatching rate of eggs at different concentrations of zinc chloride $(15,20,25$, and $30 \mathrm{mM})$ was significantly higher than that of the water control ( $p<0.05)$ (Figure 2). Zinc chloride increased the cumulative hatching of eggs. Nematodes started to hatch 10 DAI, and the cumulative hatching rate increased gradually. The highest hatching rate was $49 \%$ (at $30 \mathrm{mM}$ ). The cumulative hatching rate

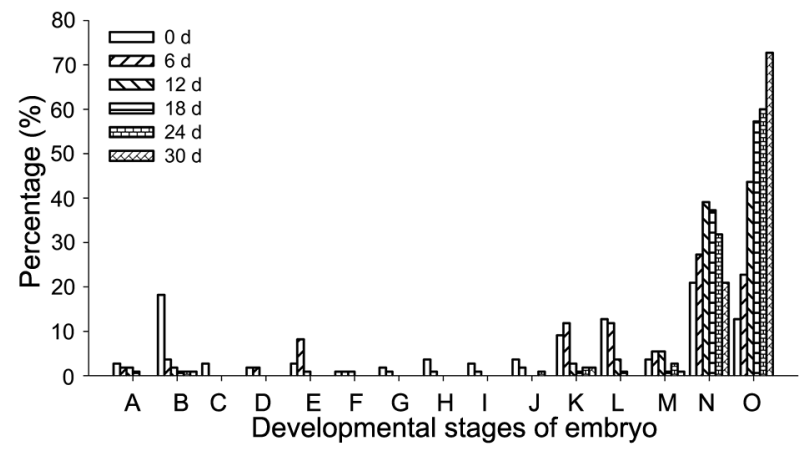

Figure 1 - Percentage of different morphological development stages of $H$. avenae white female eggs in total number changes with incubation time at $15^{\circ} \mathrm{C}$. $\mathrm{A}=$ egg; $\mathrm{B}=$ signal-cell stage; $\mathrm{C}$ $=2$-cell stage; $D$ and $E=4$-cell stage; $F-L=$ the embryo was presented as mass small cells produced after multiple division; $\mathrm{M}$ = early tadpole stage; $\mathrm{N}=$ tadpole stage.; $\mathrm{O}$ = larval. in ferric chloride at $5,10,20$, and $25 \mathrm{mM}$ was significantly higher than that of the water control $(p<0.05)$. The highest cumulative hatching rate was $13 \%$ at $10 \mathrm{mM}$. The hatching rate of eggs at different concentrations of $\mathrm{Ca}^{2+}, \mathrm{Mg}^{2+}$, and $\mathrm{Cu}^{2+}$ was not enhanced, and no significant difference between treatments and water control was observed during the experiment.

\section{Effect of inorganic ions on the hatching of free eggs in natural diapause eggs}

The results showed that the egg cumulative hatching rate in $\mathrm{Zn}^{2+}$ at 25 and $30 \mathrm{mM}$ was greater than that of other ion solutions with the same concentration at 66 DAI $(p<0.05)$, and hatching rates were $22 \%$ and $18 \%$, respectively (Figure 3). No juvenile hatched from eggs at $0-18$ DAI in $5,10,15,20$, and $30 \mathrm{mM}$ treatments. The

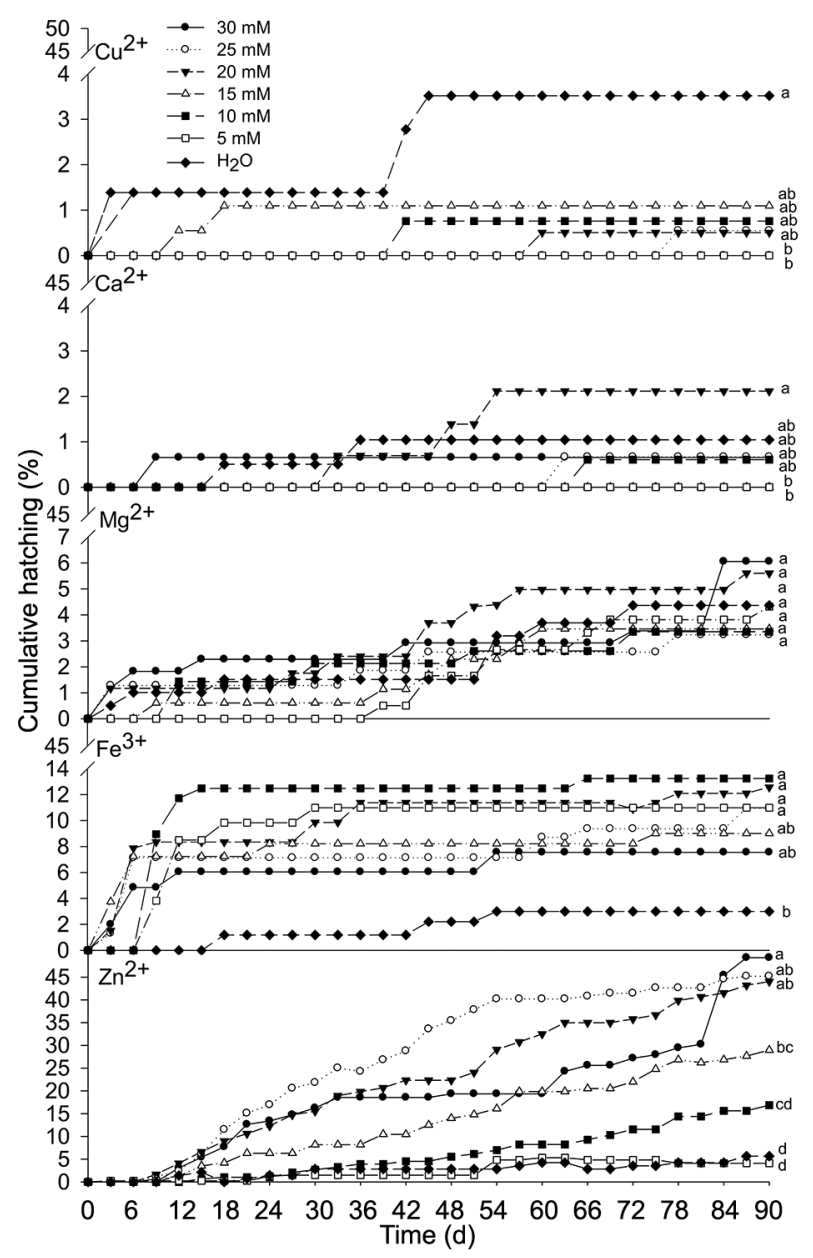

Figure 2 - Effect of different concentrations ion solution on cumulative hatching of diapause-induced eggs. $\mathrm{Ca}^{2+}, \mathrm{CaCl}_{2} ; \mathrm{Mg}^{2+}$, $\mathrm{MgCl}_{2} \cdot 6 \mathrm{H}_{2} \mathrm{O} ; \mathrm{Fe}^{3+}, \mathrm{FeCl}_{3} \cdot 6 \mathrm{H}_{2} \mathrm{O} ; \mathrm{Zn}^{2+}, \mathrm{ZnCl}_{2} ; \mathrm{Cu}^{2+}, \mathrm{CuCl}_{2} \cdot 2 \mathrm{H}_{2} \mathrm{O}$. The same letters are not significantly different by least significant different by the least significant difference (LSD, $p<0.05$ ) at 90 DAI. 


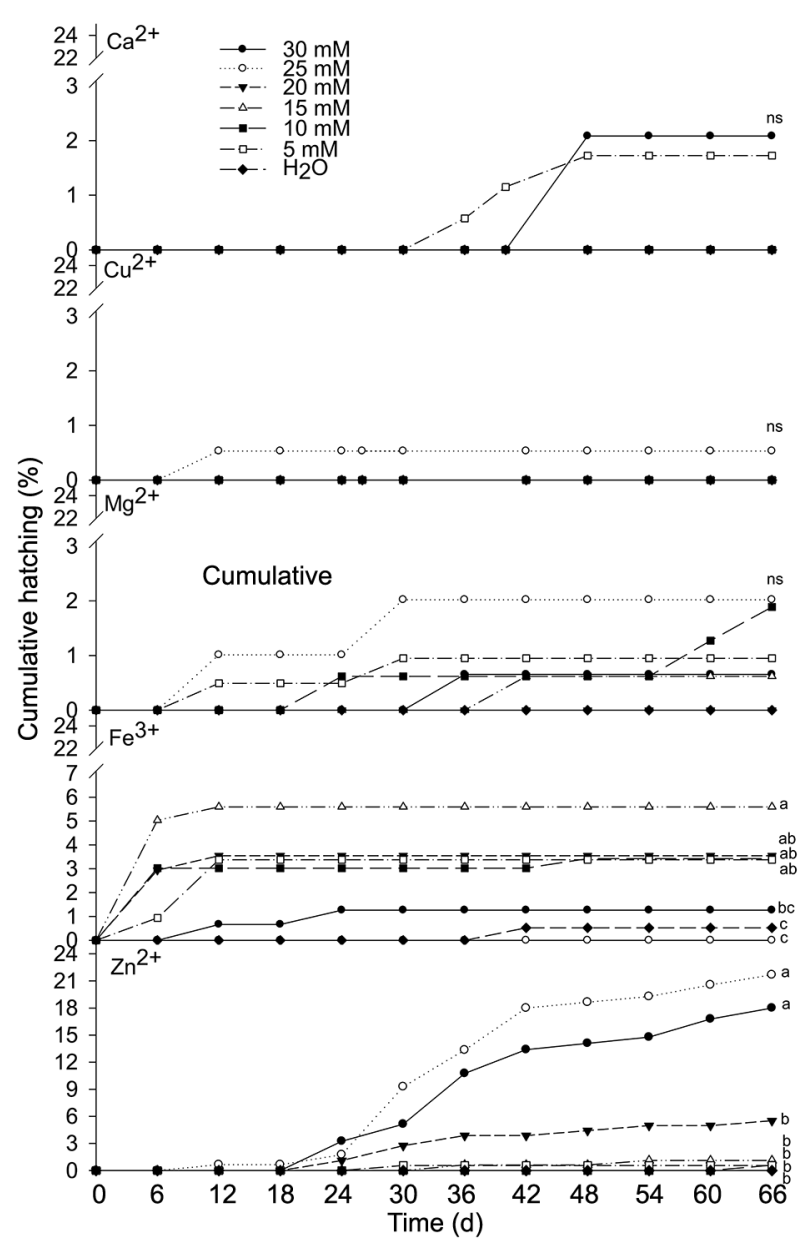

Figure 3 - Effect of different concentrations ion solution on cumulative hatching of natural diapause eggs. $\mathrm{Ca}^{2+}, \mathrm{CaCl}_{2} ; \mathrm{Mg}^{2+}$, $\mathrm{MgCl}_{2} \cdot 6 \mathrm{H}_{2} \mathrm{O} ; \mathrm{Fe}^{3+}, \mathrm{FeCl}_{3} \cdot 6 \mathrm{H}_{2} \mathrm{O} ; \mathrm{Zn}^{2+}, \mathrm{ZnCl}_{2} ; \mathrm{Cu}^{2+}, \mathrm{CuCl}_{2} \cdot 2 \mathrm{H}_{2} \mathrm{O}$. The same letters are not significantly different by the least significant difference (LSD, $p<0.05$ ) at $66 \mathrm{DAl}$; ns means no significantly different between treatments. cumulative hatching rate increased slowly after the $18^{\text {th }}$ day and no eggs hatched in the water control during the experiment period. The results showed that $\mathrm{Zn}^{2+}$ affected the hatching of diapause-induced eggs. $\mathrm{Fe}^{3+}$ solution at 5 , 10,15 , and $20 \mathrm{mM}$ stimulated the hatching of diapauseinduced eggs $(p<0.05)$, and the hatching rate increased by $3 \%-6 \%$, with the highest rate observed at $15 \mathrm{mM}$. No significant difference was observed in the cumulative hatching rate between different concentrations $\mid p>$ 0.05). In the $\mathrm{Ca}^{2+}, \mathrm{Mg}^{2+}$, and $\mathrm{Cu}^{2+}$ solution treatments, a few nematodes hatched and no significant difference was observed in cumulative hatching rate between the different concentrations and the water control (Figure 3).

\section{Effects of $\mathrm{Zn}^{2+}$ and $\mathrm{Fe}^{3+}$ solutions on the hatching of natural non-diapause eggs}

Different concentrations of $\mathrm{Fe}^{3+}$ solution inhibited the hatching of non-diapause eggs, and the hatching rate was lower than that of the water control $(p<0.05)$. Hatchability of natural non-diapause eggs in $\mathrm{Zn}^{2+}$ solution at 9, 15, 21 , and $27 \mathrm{mM}$ concentrations was significantly higher than that of the water control $(p<0.05)$. The cumulative hatching rate was $41 \%(9 \mathrm{mM}), 71 \%(15 \mathrm{mM}), 55 \%$ (21 $\mathrm{mM}), 69 \%(27 \mathrm{mM})$ and $38 \%$ (water), respectively, at 42 DAI (Table 1). The hatching rate of eggs in $\mathrm{Zn}^{2+}$ solution was higher than that in $\mathrm{Fe}^{3+}$ solution (Figure 4).

Table 1 - Cumulative hatching rate (\%) of $H$. avenae natural nondiapause eggs at different concentrations of $\mathrm{FeCl}_{3} \cdot 6 \mathrm{H}_{2} \mathrm{O}\left(\mathrm{Fe}^{+}\right)$ and $\mathrm{ZnCl}_{2}\left(\mathrm{Zn}^{2+}\right)$ solution at $42 \mathrm{DAl}$.

\begin{tabular}{lcccccc}
\hline Treatments & $\mathrm{H}_{2} \mathrm{O}$ & 3 & 9 & 15 & 21 & 27 \\
\hline & & \multicolumn{5}{c}{$\mathrm{mM}$} \\
$\mathrm{Zn}^{2+}$ & $37.5 \mathrm{~d}$ & $30.6 \mathrm{~d}$ & $40.6 \mathrm{~cd}$ & $70.5 \mathrm{a}$ & $54.9 \mathrm{bc} 69.4 \mathrm{ab}$ \\
$\mathrm{Fe}^{3+}$ & $34.7 \mathrm{a}$ & $16.6 \mathrm{~b}$ & $12.6 \mathrm{bc}$ & $7.6 \mathrm{c}$ & $11.3 \mathrm{bc}$ & $6.3 \mathrm{c}$ \\
\hline
\end{tabular}

The same letter in a row are not significantly different by least significant difference (LSD, $p<0.05)$.

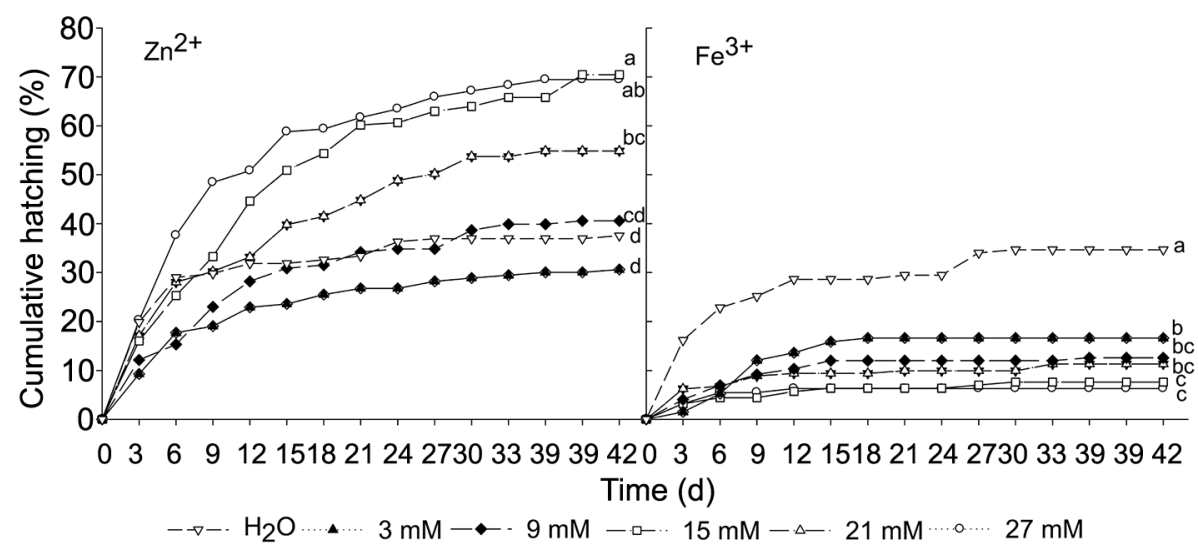

Figure 4 - Effect of different concentration $\mathrm{FeCl}_{3} \cdot 6 \mathrm{H}_{2} \mathrm{O}\left(\mathrm{Fe}^{3+}\right)$ and $\mathrm{ZnCl}_{2}\left(\mathrm{Zn}^{2+}\right)$ solution on cumulative hatching of natural non-diapause eggs. The same letters are not significantly different by the least significant difference (LSD, $p<0.05)$ at 42 DAl. 


\section{Comparison of the effect of $\mathrm{Zn}^{2+}$ solution on egg hatching in natural diapause and non-diapause eggs}

$\mathrm{Zn}^{2+}$ solution can stimulate the hatching of natural diapause and non-diapause eggs. For natural diapause eggs, no J2 hatched from eggs before the $18^{\text {th }}$ day, and the cumulative hatching rates were $1 \%(15 \mathrm{mM})$ and $13 \%(30 \mathrm{mM})$. A significant difference was observed between the treatments and water control at $42 \mathrm{DAI}$ $(p<0.05)$. Diapause eggs did not hatch until 24 (30 mM) and 35 (15 mM) DAI; in the water control, no J2 hatched from the diapause eggs during the experiment period. However, the hatching rates of natural non-diapause eggs were $69 \%$ (15 mM) and $71 \%(30 \mathrm{mM})$ at 42 DAI and were significantly higher than that of the water control $(38 \%)(p<0.05)$. No significant difference was observed between the 15 and $30 \mathrm{mM}$ treatments (Figure 5).

\section{White females response to different inorganic ions}

During the whole experiment, no juvenile hatched at different concentrations of $\mathrm{Fe}^{3+}, \mathrm{Zn}^{2+}, \mathrm{Mg}^{2+}, \mathrm{Cu}^{2+}, \mathrm{Ca}^{2+}$ solutions and in the control. Different concentrations of various inorganic ions did not stimulate the hatching of eggs inside white females.

\section{Discussion}

Previous studies have investigated the hatching of $H$. avenae (Mokabli et al., 2001; Baklawa et al., 2016). Diapause is a life stage developed by nematodes to resist bad living environment, for example, the naturally diapause in a "new" cyst of Globodera pallida is present in early spring, winter, and autumn; however, it is nonexistent in late spring and summer, which synchronized the development of its potato host plants in crops in the United Kingdom (Muhammad, 1994). In this study, hatching effected by different concentrations of various inorganic ions showed not tested ions stimulated the hatching of eggs inside white females. It shows that the different developmental stage of eggs in white females was not affected by different concentrations of various inorganic ions, which need further researcher. Females of $H$. avenae rapidly swelled into a lemon shape after mating, and the mature females changed from white to brown without the yellow stage. Therefore, eggs matured gradually during the period from white females to browning cysts. White females and new brown cysts did not hatch because of the diapause, which supported the research by $\mathrm{Li}$ et al. (2008). The cyst of $H$. avenae would undergo a diapause stage in the soil, which is important for its survival in high-temperature environment and host-free existence time after formation. No J2 hatched immediately in natural diapause (Jing et al., 2014).

Based on the study, we speculate that egg hatching was regulated by other factors, because mature eggs still could not hatch even under favorable conditions. Many factors affect the hatching of nematodes. Fall-winter season low temperature $\left(4-15^{\circ} \mathrm{C}\right)$ induced hatching of $H$. avenae, while no juveniles emergered from the cysts at high temperature $\left(20-25^{\circ} \mathrm{C}\right)$ (Jing et al., 2014). However, the effect of low temperature inducing the hatching mechanism of nematodes needs further study. Incubation of various cyst nematodes adapts to root exudates of host plants and synchronizes the life cycle of parasites with the growth of host plants, such as G. rostochiensis and G. pallida. In contrast, massive incubation of $H$. avenae lacks similar stimuli (Jones et al., 1998). In addition, the effects of different $\mathrm{pH}$ levels on the hatching of $H$. avenae were evaluated and showed that the hatching rate was the largest at $\mathrm{pH} 8.5$ (Swarup and Gill, 1972).

The impacts of inorganic ionic compounds and various nutrient elements on the hatching of nematodes have been reported in previous research; however, these studies focus mainly on the effect on hatching characteristics of potato golden nematode $(G$. rostochiensis), soybean cyst nematode (H. glycines), and beet cyst nematode (H. schachtii). G. rostochiensis juveniles inactivated by storage in distilled water for eight to ten

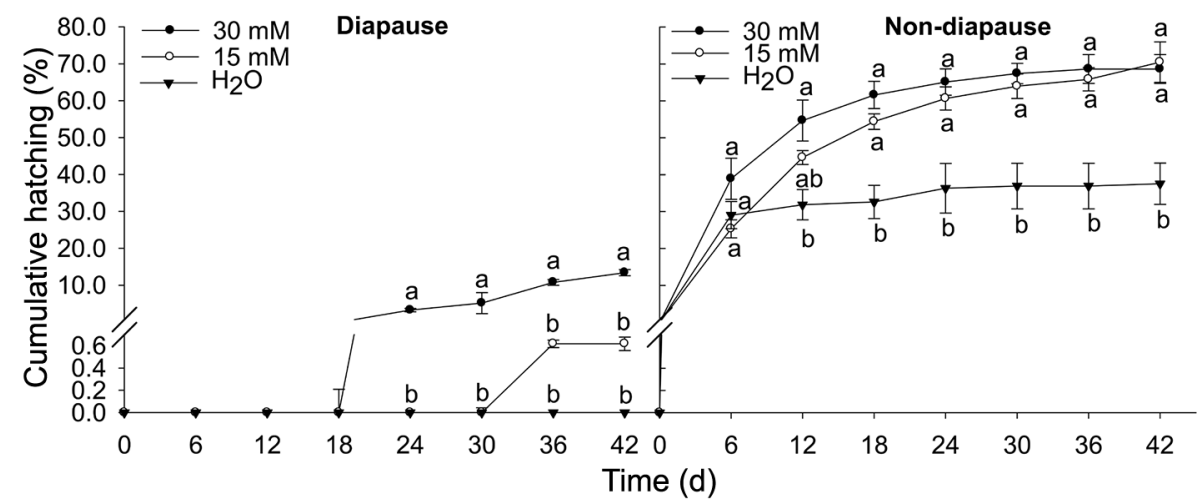

Figure 5 - Effect of different concentration $\mathrm{ZnCl}_{2}\left(\mathrm{Zn}^{2+}\right)$ solutions on cumulative hatching of the natural diapause and non-diapause egg. The same letters are not significantly different by the least significant difference (LSD, $p<0.05)$. 
days were treated with millimolar solutions of organic and inorganic hatching agents $\left(\mathrm{Ba}^{2+}, \mathrm{Zn}^{2+}, \mathrm{La}^{3+}\right)$, many juveniles were stimulated to move and $\mathrm{Ca}^{2+}, \mathrm{K}^{+}, \mathrm{Mg}^{2+}$ or $\mathrm{Na}^{+}$solutions had no stimulus on hatching (Clarke and Hennessy, 1987). The hatching ability of white females formed by the first generation of $H$. glycines was higher than that of the brown cyst, whereas the cyst of white or newly formed $H$. avenae did not hatch under favorable temperature (Li et al., 2008). Previous studies have shown that inorganic salt solution has three effects on cyst-form nematodes: stimulus for eggs to hatch, hatching inhibition, and no response on hatching, which depend on the kinds and concentrations of ions; however, the zinc solution is believed to have no effect on $H$. avenae hatching in those studies (Clarke and Shepherd, 1966). The reason for ingironing this important catalytic effect on hatching is that, in the previous studies, only low concentration $3-4$ $\mathrm{mM}$ ) ion solutions were tested. This study attempted to use the precise concentration gradient and four different eggs and investigate, for diapause induced eggs, $5-30$ $\mathrm{mM} \mathrm{Cu}{ }^{2+}$ inhibiting the egg hatching, $\mathrm{Ca}^{2+}$ and $\mathrm{Mg}^{2+}$ have no response on hatching, while $5-30 \mathrm{mM} \mathrm{Fe}^{3+}$ stimulated egg hatching. Low concentration (less than 10 $\mathrm{mM}) \mathrm{Zn}^{2+}$ had no effect on egg hatching, but $15-30 \mathrm{mM}$ $\mathrm{Zn}^{2+}$ showed stimulating effect to egg hatching.

Our results showed that the $\mathrm{Zn}^{2+}$ solution had obvious stimulatory effects on diapause induced and non-diapause $H$. avenae eggs and had greater hatching stimulatory effect in non-diapause than in diapause eggs with high concentrations (15 and $30 \mathrm{mM})$. These results confirmed that the concentration of inorganic salt an important factor on hatching, whereas the $\mathrm{Fe}^{3+}$ solution weakly stimulated the hatching of diapause eggs and inhibited the hatching of non-diapause eggs. The elimination of osmotic stress by releasing solute is necessary for incubation, at the same time, the activity of juveniles were related to the osmotic pressure of the solution and the change of egg-shell permeability (Clarke and Hennessy, 1987). Therefore, the effect of concentration on hatching may be due to the change of osmotic pressure inside and outside the egg-shell caused by different concentrations of solution.

Calcium chloride, magnesium chloride, and copper chloride had no significant effect on hatching in this study. Interestingly, the mechanism of hatching in $\mathrm{Zn}^{2+}$ and $\mathrm{Fe}^{3+}$ solutions was different. J2s that hatched in zinc chloride were active; however, those hatched in $\mathrm{Fe}^{3+}$ were stiff and immotile. Moreover, the hatching of diapause eggs in $\mathrm{Fe}^{3+}$ occurred mainly in the first two weeks of the experiment; thus, the authors concluded that $\mathrm{Fe}^{3+}$ might have stimulated certain developmental stage eggs. $\mathrm{Zn}^{2+}$ stimulation has been reported to increase the activity of leucine aminopeptidase and a probable zinc metalloenzyme that is involved in egg hatching and supplemented by zinc (Behm et al., 1995). Perry and Moens (2011) deduced that some kind of compound promoted hatching because of the destructive ability of the lipoprotein membrane in egg shells, making J2 easier to break out of the shell. $\mathrm{Zn}^{2+}$ has the ability to displace the bound $\mathrm{Ca}^{2+}$ that may have a structural role in eggshell impermeability from the lipoprotein layer of the eggshell (Clarke and Perry, 1985). Therefore, the stimulating effect of $\mathrm{Zn}^{2+}$ on hatching may be due to the stimulus for movement of juveniles in the eggs and changing eggshell permeability.

In this study, the results comfirmed that $\mathrm{Zn}^{2+}$ and $\mathrm{Fe}^{3+}$ affect the hatching of $H$. avenae in vitro. The effect of different concentration of $\mathrm{Zn}^{2+}$ and $\mathrm{Fe}^{3+}$ on nematode hatching should be tested in vivo in further studies. Then, the specific ions concentration was determined. In soil, zinc and iron are the essential micronutrients for plant growth (Singh et al., 2018); however, they are soil heavy metals and excessive application of these inorganic ions could be harmful to soil biodiversity and physicochemical properties (Jalali and Hemati, 2013). Therefore, if fertilizers containing inorganic ions were applied to the soil, they could provide nutrition to plants and control nematodes as well; however, further studies are necessary to determine dosage and proportion of zinc, iron ions.

\section{Conclusion}

In this study, the results revealed that ion concentration is a key factor that affects hatching. Zinc and iron ions have obvious effects on the hatching of $H$. avenae. $\mathrm{Zn}^{2+}$ can significantly promote the hatching of diapause and non-diapause eggs. $\mathrm{Fe}^{3+}$ has an inhibitory effect on non-diapause egg hatching in this experiment; however, it promotes the hatching of natural diapause eggs at 5,10,15, and $20 \mathrm{mM}$ concentrations. Based on the effect of different inorganic ions on the hatching of eggs, the corresponding inorganic ions could be added to fertilizers, which could provide useful information for the development of new methods for nematode control.

\section{Acknowledgments}

This research was funded the National Natural Science Foundation of China (31660511). We would like to thank EssayStar (http://essaystar.com/) for the English language editing of this manuscript.

\section{Authors' Contributions}

Conceptualization: $\mathrm{Wu}, \mathrm{H} . \mathrm{Y}$.; Li, T.J. Data acquisition: Li, T.J. Design of methodology: Li, T.J.; Wu, H.Y. Data analysis: Wang, D.Y.; Li, B.X. Writing and editing: $\mathrm{Li}$, T.J.; Wu, H.Y.

\section{References}

Baklawa, M.; Niere, B.; Massoud, S. 2016. Influence of temperature and storage conditions on the hatching behavior of cereal cyst nematodes (Heterodera avenae, Wollenweber) from Egypt. Journal of Plant Diseases and Protection 124: 1-13. 
Behm, J.E.; Tylka, G.L.; Niblack, T.L.; Wiebold, W.L.; Donald, P.A. 1995. Effects of zinc fertilization of corn on hatching of Heterodera glycines in soil. Journal of Nematology 27: 164171.

Calderón-Urrea, A.; Vanholme, B.; Vangestel, S.; Kane, S.M.; Bahaji, A.; Pha, K.; Garcia, M.; Snider, A.; Gheysen, G. 2016. Early development of the root-knot nematode Meloidogyne incognita. BMC Developmental Biology 16: 10-24.

Čepulytè-Rakauskienè, R.; Būda, V. 2015. The effects of $\alpha$-solanine and zinc sulphate on the behaviour of potato cyst nematodes Globodera rostochiensis and G. pallida. Nematology 17: 11051111.

Charlson, D.V.; Tylka, G.L. 2003. Heterodera glycines cyst components and surface disinfestants affect $H$. glycines hatching. Journal of Nematology 35: 458-564.

Clarke, A.J.; Hennessy, J. 1981. Calcium inhibitors and the hatching of Globodera rostochiensis. Nematologica 27: 190-198.

Clarke, A.J.; Hennesy, J. 1987. Hatching agents as stimulants of movement of Globodera rostochiensis juveniles. Revue Nématologie 10: 471-476.

Clarke, A.J.; Perry, R.N. 1985. Egg-shell calcium and the hatching of Globodera rostochiensis. International Journal for Parasitology 15: 511-516.

Clarke, A.J.; Shepherd, A.M. 1965. Zinc and other metallic ions as hatching agents for the beet cyst nematode, Heterocdera schachtii Schm. Nature 208: 502-502.

Clarke, A.J.; Shepherd, A.M. 1966. Inorganic ions and the hatching of Heterodera spp. Annals of Applied Biology 58: 497-508.

Dackman, C.; Nordbring-Hertz, B. 1985. Fungal parasites of the cereal cyst nematode Heterodera aoenae in southern Sweden. Journal of Nematology 17: 50-55.

Hou, S.Y.; Wang, A.L.; Zhang, G.; Huang, L.L. 2012. Effect of cereal cyst nematode on agronomic characteristics and yield losses of spring wheat. Journal of Agriculture 2: 31-36 (in Chinese, with abstract in English).

Ibrahim, A.A.M.; Al-Hazmi, A.S.; Al-Yahya, F.A.; Alderfasi, A.A. 1999. Damage potential and reproduction of Heterodera avenae on wheat and barley under Saudi field conditions. Nematology 1: 625-630.

Jalali, M.; Hemati, N. 2013. Chemical fractionation of seven heavy metals $(\mathrm{Cd}, \mathrm{Cu}, \mathrm{Fe}, \mathrm{Mn}, \mathrm{Ni}, \mathrm{Pb}$, and $\mathrm{Zn})$ in selected paddy soils of Iran. Paddy Water Environment 11: 299-309.

Jing, B.X.; He, Q.; Wu H.Y.; Peng, D.L. 2014. Seasonal and temperature effects on hatching of Heterodera avenae (Shandong population, China). Nematology 16: 1209-1217.

Jones, P.W.; Tylka, G.L.; Perry, R.N. 1998. The physiology and biochemistry of free-living and plant-parasitic nematodes. $\mathrm{CAB}$ International, Wallingford, UK.

Kerry, B.R.; Crump, D.H.; Mullen, L.A. 1982. Natural control of the cereal cyst nematode, Heterodera aoenae Woll., by soil fungi at three sites. Crop Protection 1: 99-109.

Lehman, P.S.; Barker K.R.; Huisingh, D. 1971. Effects of $\mathrm{pH}$ and inorganic ions on emergence of Heterodera Glycines. Nematologica 17: 467-473.

Li, B.X.; Luo, M.; Wu, H.Y. 2020. Proteomic analysis of Heterodera glycines: comparison for white females and brown cysts. International Journal of Agriculture and Biology 23: 857-862.
Li, X.X.; Wu, H.Y.; Shi, L.B.; Wang, Z.H.; Yu, H. 2008. Comparison of several metabolites in white cysts and brown cysts of soybean cyst nematode. Soybean Science 27: 283-287 (in Chinese, with abstract in English).

Masler, E.P.; Rogers, S.T. 2011. Effects of cyst components and low temperature exposure of Heterodera glycines eggs on juvenile hatching in vitro. Nematology 13: 837-844.

Mathur, B.N.; Handa, D.K.; Swaroop, S.; Sethi, C.L.; Sharma, G.L.; Yadav, B.D. 1980. On the loss estimation and chemical control of molya disease of wheat caused by Heterodera avenae in India. Indian Journal of Nematology 16: 152-159.

Mokabli, A.; Valette, S.; Gauthier, J.P.; Rivoal, R. 2001. Influence of temperature on the hatch of Heterodera avenae Woll. populations from Algeria. Nematology 3: 171-178.

Muhammad, Z. 1994. Diapause in the nematode Globodera pallida. European Journal of Plant Pathology 100: 413-423.

Palomares-Rius, J.E.; Jones, J.T.; Cock, P.T.; Castillo, P.; Blok, V.C. 2013. Activation of hatching in diapaused and quiescent Globodera pallida. Parasitology 140: 445-454.

Perry, R.N.; Moens, M. 2011. Survival of parasitic nematodes outside the host. In: Perry, R.N.; Wharton, D.A., eds. Molecular and physiological basis of nematode survival. $\mathrm{CAB}$ International, Wallingford, UK.

Schulze, J.; Schierenberg, E. 2011. Evolution of embryonic development in nematodes. EvoDevo 2: 18. https://doi. org/10.1186/2041-9139-2-18

Singh, D.; Geat, N.; Rajawat, M.V.S.; Prasanna, R.; Kar, A,; Singh, A.M.; Saxena, A.K. 2018. Prospecting endophytes from different Fe or $\mathrm{Zn}$ accumulating wheat genotypes for their influence as inoculants on plant growth, yield, and micronutrient content. Annals of Microbiology 68: 815-833.

Steele, A.E.; Toxopeus, H.; Heijbroek, W.A. 1982. Comparison of the hatching of juveniles from cysts of Heterodera schachtii and H. trifolii. Journal of Nematology 14: 588-592.

Swarup, G.; Gill, J.S. 1972. Factors influencing emergence of larvae from cysts of Heterodera avenae. Indian Journal of Experimental Biology 10: 219-223.

Toumi, F.; Waeyenberge, L.; Viaene, N.; Dababat, A.A.; Nicol, J.M.; Ogbonnaya, F.; Moens, M. 2017. Cereal cyst nematodes: importance, distribution, identification, quantification, and control. European Journal of Plant Pathology 150: 1-20.

Vandenbossche, B.A.; Niere, B.; Vidal, S. 2015. Effect of temperature on the hatch of two German populations of the beet cyst nematodes, Heterodera schachtii, and Heterodera betae. Journal of Plant Diseases and Protection 122: 250-254.

Wu, H.Y.; He, Q.; Liu, J.; Luo, J.; Peng, D.L. 2014. Occurrence and development of the cereal cyst nematode (Heterodera avenae) in Shandong, China. Plant Disease 98: 1654-1660.

Yen, J.H.; Niblack, T.L.; Wiebold, W.J. 1995. Dormancy of Heterodera glycines in Missouri. Journal of Nematology 27: 153-163.

Zhang, D.L.; Wang, H.Y.; Ji, X.X.; Wang, K.Y.; Wang, D.; Qiao, K. 2017. Effect of abamectin on the cereal cyst nematode (CCN, Heterodera avenae) and wheat yield. Plant Disease 101: 973976.

Zhang, S.; Gan, Y.; Xu, B. 2014. Efficacy of Trichoderma longibrachiatum in the control of Heterodera avenae. BioControl 59: 319-331. 